\title{
Brugada症候群に合併した発作性心房細動への カテーテルアブレーション
}

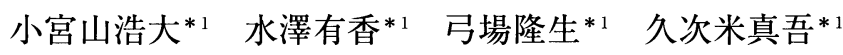
辰本明子*1 田辺康宏*1 深水誠二*1 山口博明*1 岡崎英隆 ${ }^{* 1}$ 手島 保*1 櫻田春水*1 西崎光弘 ${ }^{* 2}$ 平岡昌和*3

Brugada症候群では発作性心房細動(PAF)が20\%に合併し，かつ電気生理検査に より高率に誘発されることが知られている。，一方Brugada症候群に伴う心房細動 (AF)の発生機序は明らかでない.しかも多くの抗不整脈薬は右側胸部誘導のcoved 型ST 上昇を増悪させ, さらにphase2リエントリーから心室細動を起こすリスクが ある. そのため, AFの治療に用いることができず治療に難渋するケースが多い，わ れわれはBrugada 症候群に合併したPAFに対するカテーテルアブレーションを4例 (4 本の肺静脈隔離 1 例, circumferential PV isolation 3 例) 経験した. いずれの症例 も通常みられる AF と同様に肺静脈からの期外収縮を認め, 肺静脈の電気的隔離を行 うことで3 例 $(75 \%$ )で発作が抑制された. Brugada症候群に伴うAFに対し，カテー テルアブレーションは有効な治療になりえると思われた.

\section{I 。はじめに}

Brugada症候群は右側前胸部誘導にて特徴的な ST 上昇 (coved 型, saddle-back型) を呈し, 器質的 心疾患を伴わず心室細動 $(V F)$ を発症する疾患であ

\begin{tabular}{|c|c|}
\hline Keywords & $\begin{array}{l}\text { - Brugada症候群 } \\
\text { - 心房細動 } \\
\text { - カテーテルアブレーション } \\
\text { - 肺静脈隔離術 }\end{array}$ \\
\hline
\end{tabular}

*1東京都立広尾病院循環器科

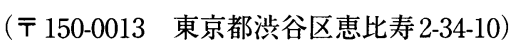

$* 2$ 横浜南共済病院循環器内科

$* 3$ 東京医科歯科大学
$り^{11}$ ，若年から中年男性に多く認められる。また Brugada症候群の $20 \%$ に房細動 (AF) を合併する ことが報告されており, 電気生理検査 $(\mathrm{EPS})$ により 高率にAFが誘発されやすい2，3). Brugada症候群に 伴う $\mathrm{AF}$ 発生機序については明らかにされていない が，心室筋同様に心房筋における電気生理学的異常 の存在が推測されている。多くの $\mathrm{Na}$ チャネル遮断 薬はVFを誘発する可能性があるため，AFに対する 抗不整脈薬の選択には限界がある。一方で， $\mathrm{AF}$ は そのトリガーとなる肺静脈 (PV) からの期外収縮を 標的としたアブレーションにより，根治可能である

Catheter ablation for paroxysmal atrial fibrillation concomitant with Brugada syndrome

Kota Komiyama, Yuka Mizusawa, Takao Yuba, Shingo Kujime, Akiko Tatsumoto, Yasuhiro Tanabe, Seiji Fukamizu, Hiroaki Yamaguchi, Hidetaka Okazaki, Tamotsu Tejima, Harumizu Sakurada, Mitsuhiro Nishizaki, Masayasu Hiraoka 
表 1 患者一覧

\begin{tabular}{c|cccc} 
& 症例1 & 症例2 & 症例3 & 症例4 \\
\hline \hline 性 & 男性 & 男性 & 男性 & 男性 \\
年齢 & 41 & 50 & 52 & 67 \\
ECG & 薬阂coved & 薬剂coved & 自然coved & 自然coved \\
AF症状 & + & + & + & + \\
VF歴/失神歴 & $-/-$ & $-/-$ & $\mathrm{VF} /+$ & $-/-$ \\
家族歴 & - & - & + & - \\
isolation type & CPVI & $4 \mathrm{PVI}$ & $4 \mathrm{PVI}$ & $4 \mathrm{PVI}$
\end{tabular}

CPVI : circumferential PV isolation, 4PVI：各々4本の肺静脈隔離.

ことが示されている ${ }^{4)}$. 今回われわれは Brugada 症 候群に合併した $\mathrm{AF}$ のカテーテルアブレーション を4例経験したので報告する.

\section{II. 対象と方法}

\section{1. 対象}

対象はBrugada 型心電図を呈した 4 症例 (男性, 平均年齢は $52.5 \pm 18.4$ 歳)である. 自然に coved 型を 呈した症例と，ピルジカイニド負荷にて coved型を 呈した症例はともに 2 症例であった。 そのうち心臓 突然死の家族歴を有するものは 1 症例 (症例 3$)$ で, VF歴を有するものと同一であった４症例すべてに おいて $\mathrm{AF}$ 自覚症状が強く, 患者からの希望によ りカテーテルアブレーションを選択した(表1).

\section{2. 方法}

(1) 心電図

Brugada症候群の診断は, Wilde らが報告した consensus reportに従った ${ }^{5)}$. Type 2, type 3 のみ の症例にはピルジカイニド $1 \mathrm{mg} / \mathrm{kg} / 10 \mathrm{~min}$ 用い, type 1へ変化したものとした. EPSにて全例でVF が誘発されており, Brugada症候群と診断された.

(2) 電気生理検査(EPS) およびアブレーション
AFおよびVFを誘発するため，患者とその家族か ら同意を得た後に，経皮的に左右大腿静脈から挿入 した4極電極カテーテルをそれぞれ高位右房(HRA)， His 束 $(\mathrm{HBE})$, 右室心尖部 (RVA), 右室流出路 (RVOT)に留置しEPSを施行した。

心房刺激は HRA から, 基本周期 $600 \mathrm{~ms}$ と $400 \mathrm{~ms}$ の 2 連期外刺激までと， $230 \mathrm{~ms}$ までを頻回に行った。

心室刺激は RVA およびRVOTから，基本周期 $600 \mathrm{~ms}$ と $400 \mathrm{~ms}$ の 3 連期外刺激(S2S3は $180 \mathrm{~ms}$ まで, $\mathrm{S} 3 \mathrm{~S} 4$ は $200 \mathrm{~ms}$ まで。その範囲内で捕捉可能な S3S4

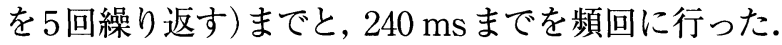

(3) 肺静脈隔離術 (PVI)

Haissaguerre らが考案した電気生理学的アプロー チによる各々 4 本の肺静脈隔離術 $(4 \mathrm{PVI})^{6)}$ と, CARTO システム (Biosense, Cordis Webstar)を用 いた解剖学的アプローチによる同側上下両PVをラ インで囲むように隔離する circumferential PV isolation $(\mathrm{CPVI})^{7}$ のいずれかを 4 症例に対し施行した.

いずれの方法でも PV 入口部に多極リング状カテー テルを留置し，PV起源の期外収縮の有無を観察し， arrhythmogenic veins同定後にアブレーションを 行った(図1). 


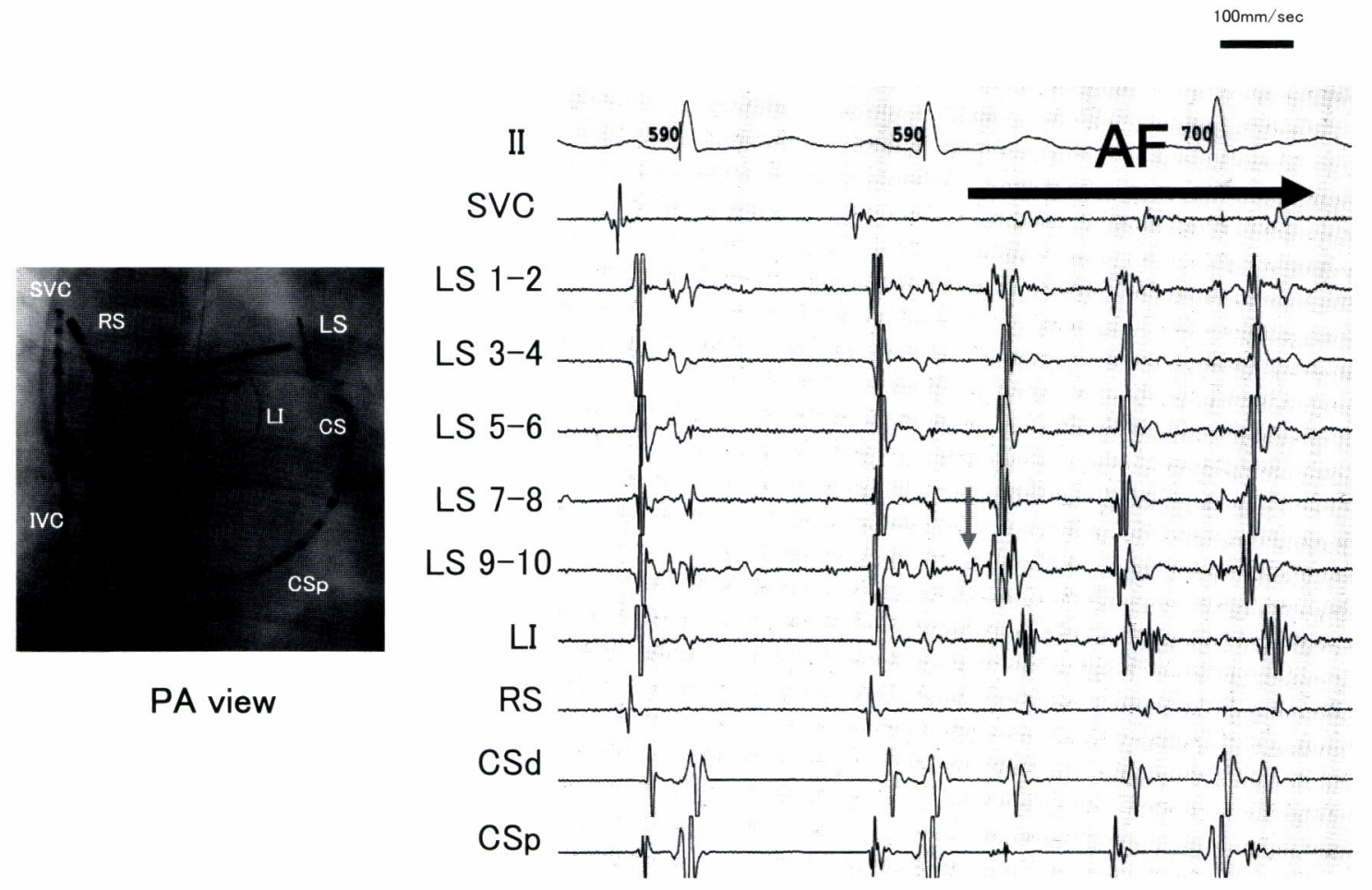

図1 症例 1 の肺静脈起源の期外収縮頻発から心房細動へ移行している所見

SVCに 4 極電極カテーテル, IVCに 4 極電極カテーテル, CSに 10 極電極カテーテル, RSに 4 極電極カテーテル, LSに 10 極電極りング状カテーテル，LIに10極電極リング状カテーテルを挿入している.

$\downarrow$ : LS 起源の期外収縮, SVC : 上大静脈, IVC : 下大静脈, CS : 冠状静脈, RS : 右上肺静脈, LS : 左上肺静 脈, LI : 左下肺静脈.

4PVIでは, $8 \mathrm{~mm}$ tip アブレーションカテーテル を用い, 最大出力 $35 \mathrm{~W}$, 最高温度 53 度で電気的に 4 本のPVを左房から隔離した.

解剖学的アプローチでは, $4 \mathrm{~mm}$ tip アブレーショ ンカテーテルを用い, 最大出力 $35 \mathrm{~W}$, 最高温度 53 度でCARTO ガイド下にて同側上下両PVを電気的 に隔離した(図2)。アブレーションのエンドポイン トは，コントロールおよびイソプロテレノール(ISP) 負荷時の両方行性ブロックを認めることとした.

またすべての症例において, 三尖弁一大静脈間峡 部の線状アブレーションを行い, 両方向性ブロック を確認した。

\section{III. 結果}

EPS では 4 症例全例に心房刺激を加えると再現性 をもって容易に $\mathrm{AF}$ が誘発され，いずれの症例でも S-4-34
心房の受攻性が立進していることが示された。また， 心室刺激を加えると再現性をもって全例にVFが誘 発された。全例で $P V$ 起源の期外収縮の頻発を認め た.アブレーション後， 4 症例ともにコントロールお よびISP負荷時の両方行性ブロックが確認された. ほかの上室性不整脈は, 通常型心房粗動が 2 症例で 誘発された。観察期間は $23.5 \pm 20.5$ カで, $\mathrm{AF}$ の再 発は 3 例で認めなかった(抑制率 $75 \%$ )。AFの再発 を認めた 1 例では, AF 時の心室応答が速く植込み 型除細動器 (ICD)の誤作動を招いた(表2).

\section{IV. 考察}

Brugada症候群の特徵的な右側胸部誘導でのST 上昇とVF発作は, Antzelevitchらの動物実験モデ ルでの検討からRVOT心筋における再分極異常によ り説明されている ${ }^{8}$.

JPN. J. ELECTROCARDIOLOGY VOI. 27 SUPPL. 42007 
Ablation site

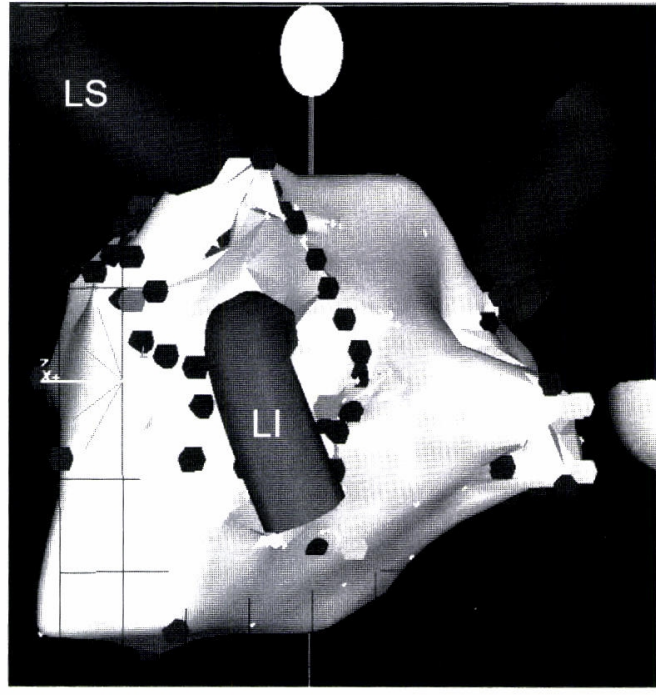

Left PVs

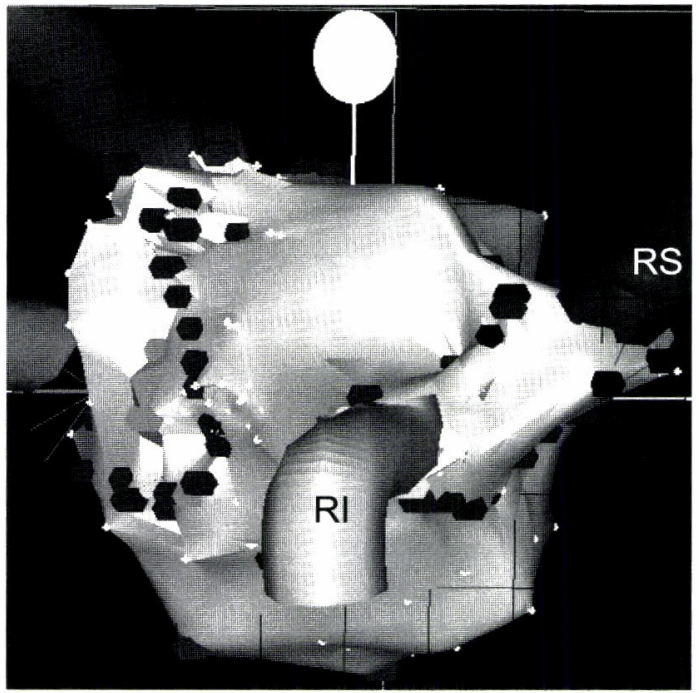

Right PVs

図 2 CARTO system を用いた CPV1例

CARTOガイド下にて同側上下両 PVを電気的に隔離している(症例1)。

表24症例の結果

\begin{tabular}{c|cccc} 
& 症例1 & 症例2 & 症例3 & 症例4 \\
\hline \hline isolation type & CPVI & $4 P V I$ & $4 P V I$ & $4 P V I$ \\
EPSでのAF誘発 & 誘発 & 誘発 & 誘発 & 誘発 \\
$\begin{array}{c}\text { PVからの } \\
\text { 期外収縮頻発 }\end{array}$ & + & + & + & + \\
ほかの不整脈 & - & C-AFL & C-AFL & - \\
$\begin{array}{c}\text { 観察期間(月) } \\
\text { AF再発 }\end{array}$ & 14 & 22 & 30 & 43 \\
& - & - & ICD誤作動 & -
\end{tabular}

EPSでは全例に AF が誘発され，全例にPV 起源の期外収縮が頻回に認められた。ほかの 上室性不整脈では, 症例 2 と 3 に通常型心房粗動が認められた。 $\mathrm{AF}$ の再発は 3 例 (症例 1 , $2 ， 4)$ では認めなかった(抑制率 $75 \%$ )が症例 3 で認められた。

CPVI : circumferential PV isolation, 4PVI : 各々4本の肺静脈隔離, c-AFL : 通常型心 房粗動. 
Brugada症候群の 20 ～39\%に上室性頻脈を認め ることが報告されている ${ }^{2)}$. なかでも AFはBrugada 症候群の $39 \%$ に合併し，EPSにより $57.1 \%$ で誘発さ れたという報告がある ${ }^{3)}$. すなわち Brugada症候群 では心房受攻性が充進しており，心室筋のみならず 心房筋にも電気生理学的異常が存在することが考え られる。

しかしその一方で Naチャネル遮断薬には, 右側 胸部誘導上のST上昇を惹起しVFを発生しうる催不 整脈作用がある ${ }^{9}$ ため, Brugada症候群に伴う AFに 使用できる抗不整脈薬の選択は限られる.

今回われわれは, AFを伴う4例のBrudaga症候 群に対し PV isolationを行い，3例(75\%)でAFを抑 制できた。これはBrugada症候群に伴う AFでも， トリガーとなる期外収縮が発生する PVを電気的に 隔離するアブレーションによって抑制できることを 示唆している. またBrugada症候群では心房受攻性 が充進しているため異常な substrateが推測される が, 図1に示したようにPVからの期外収縮頻発より $\mathrm{AF}$ 一移行する所見が全例に認められており，PVの 電気的隔離により $\mathrm{AF}$ が抑制できたものと思われる.

したがってカテーテルアブレーションによる電気 的 PV 隔離術は, AFを伴う Brugada症候群患者の QOL 改善や ICD 誤作動の減少に役立つ可能性があ る.ただしBrugada症候群の病態についてはまだ不 明な点もあり,長期的な経過観察が必要と考えられる.

\section{V. 結 語}

Brugada症候群に伴う AFの治療には, カテーテ ルアブレーションも選択肢の一つになりえると思わ れた.

\section{〔文献〕}

1 ) Brugada P, Brugada J : Right bundle branch block, persistent ST segment elevation and sudden cardiac death : a distinct clinical and electrocardiographic syndrome. A multicenter report. J Am Coll Cardiol, $1992 ; 20: 1391 \sim 1396$

2 ) Eckardt L, Kirchhof P, Loh P, Schulze-bahr E, Johna R, Wichter T, Breithardt G, Haverkamp W, Borggrefe M : Brugada syndrome and supraventricular tachyarrhythmias : a novel association? J Crdiovasc Electrophysiol, $2001 ; 12: 680 \sim 685$

3 ) Morita H, Kusano-Fukushima K, Nagase S, Fujimoto Y, Hisamatsu K, Fujio H, Haraoka K, Kobayashi M, Morita ST, Nakamura K, Emori T, Matsubara H, Hina K, Kita $\mathrm{T}$, Fukutani $\mathrm{M}$, Ohe $\mathrm{T}$ : Atrial fibrillation and atrial vulnerability in patients with Brugada syndrome. J Am Coll Cardiol, $2002 ; 40: 1437 \sim 1444$

4 ) Haissaguerre M, Jais P, Shah DC, Takahashi A, Hocini M, Quiniou G, Garrigue S, Mouroux AL, Metayer PL, Clementy J : Spontaneous initiation of atrial fibrillation by ectopic beats originating in the pulmonary veins. $\mathrm{N}$ England J Med, $1998 ; 339: 659 \sim 666$

5 ) Wilde AA, Antzelevitch C, Borggrefe M, Brugada J, Brugada R, Brugada P, Corrado D, Hauer RN, Kass RS, Nademanee K, Priori SG, Towbin JA ; Study Group on the Molecular Basis of Arrhythmias of the European Society of Cardiology : Proposed diagnostic criteria for the Brugada syndrome : consensus report. Circulation, $2002 ; 106: 2514 \sim 2519$

6 ) Haissaguerre M, Shah DC, Jais P, Hocini M, Yamane T, Deisenhofer I, Chauvin M, Garrigue S, Clementy J : Electrophysiological breakthroughs from the left atrium to the pulmonary veins. Circulation, $2000 ; 102: 2463 \sim 2465$

7 ) Pappone C, Oreto G, Rosanio S, Vicedomini G, Tocchi M, Gugliotta F, Salvati A, Dicandia C, Calabro MP, Mazzone P, Ficarra E, Gioia C, Gulletta S, Nardi S, Santinelli V, Benussi S, Alfieri O : Atrial electroanatomic remodeling after circumferential radiofrequency pulmonary vein ablation : efficacy of an anatomic approach in a large cohort of patients with atrial fibrillation. Circulation, $2001 ; 104: 2539 \sim 2544$

8 ) Antzelevitch C, Brugada P, Brugada J, Brugada R, Towbin JA, Nademanee K : Brugada syndrome : 19922002 : a historical perspective. J Am Coll Cardiol, 2003 ; $41: 1665 \sim 1671$

9 ) Brugada R, Brugada J, Antzelevitch C, Kirsch GE, Potenza D, Towbin JA, Brugada P : Sodium channel blockers identify risk for sudden death in patients with ST-segment elevation and right bundle branch block but structurally normal heats. Circulation, $2000 ; 8$ : $510 \sim 515$ 